\title{
RUPTURE OF SECOND TRIMESTER ECTOPIC PREGNANCY IN A NON COMMUNICATING UTERINE HORN
}

Prabhakar Shivajirao Gawandi, Chandracant Jadhave, Magala Asoke Shinde, Vidya. Ramdas Tirankar

1. Assistant Professor, Department of Obstetrics \& Gynaecology, DR V.M.M.C, Solapur, Maharashtra.
2. Assistant Professor, Department of Obstetrics \& Gynaecology, DR V.M.M.C, Solapur, Maharashtra.
3. Professor, Department of Obstetrics \& Gynaecology, DR V.M.M.C, Solapur, Maharashtra.
4. Associate Professor, Department of Obstetrics \& Gynaecology, DR V.M.M.C, Solapur, Maharashtra.

CORRESPONDING AUTHOR

Dr. Prabhakar Shivajirao Gawandi, Laxmi Apartment, Flat No 4, Near Ramand Home Karbse Bungalow

North Sadar Bazaar, Maharashtra Solapur 413003

E-mail: dr.prabhakar.gawand@gamail.com

Ph: 00919823737073

ABSTRACT: Term pregnancy in a non communicating rudimentary horn of the uterus is extremely rare and usually terminates in rupture during second trimester of pregnancy. Diagnosis of rudimentary horn pregnancy and its rupture in a woman with prior vaginal delivery is difficult. It can be missed in routine ultrasound scan and in majority of cases it is detected after rupture. It requires a high index of suspicion. Because of muscular constitution of the uterine horn, pregnancy continues up to second trimester. When uterine rupture occurs, it manifests as a case of acute abdomen with increased risk of maternal mortality. The rudimentary horn may or may not communicate with the uterine cavity, majority of cases being in a non communicating horn. Here, we present a case of pregnancy which was diagnosed clinically as a case of abdominal pregnancy and on laparotomy diagnosis of pregnancy from ruptured non communicating uterine horn was made.

CASE SUMMARY: - G2P1L1 with rupture rudimentary horn pregnancy at 14weeks of gestation which was diagnosed as abdominal pregnancy with fetal demise by ultrasound, and case referred to our hospital. 0/E patient was conscious, oriented, pulse rate 104/min, B.P. 110/70 $\mathrm{mm}$ of $\mathrm{Hg}$, severe pallor noted. . On per abdominal examination generalised tenderness and guarding were present and exact uterine height was not appreciated. On per speculum examination healthy cervix with closed os and no bleeding found. On per vaginal examination, forniceal tenderness was present and exact uterine size was not appreciated due to tenderness. Laparotomy revealed rupture of right rudimentary horn pregnancy with massive hemoperitoneum. Timely laparotomy, excision of the horn, and blood transfusion saved the patient.

KEYWORDS: second trimester, ectopic pregnancy, a non communicating rudimentary horn.

INTRODUCTION: Pregnancy in a rudimentary horn of the uterus is rare and represents a form of ectopic gestation. Despite advances in ultrasound, prenatal diagnosis is difficult and final diagnosis being made on laparotomy. Because of muscular constitution of the uterine horn, pregnancy continues up to second trimester. When uterine rupture occurs, it manifests as a case of acute abdomen with increased risk of maternal mortality. The rudimentary horn may or may not communicate with the uterine cavity, majority of cases being in a non communicating horn. 
Here, we present a case of pregnancy which was diagnosed clinically as a case of abdominal pregnancy and on laparotomy; diagnosis of pregnancy from ruptured non communicating uterine horn was made.

A 26 years old patient, second gravida with previous full term vaginal delivery with 4 months of amenorrhoea came with chief complaint of pain in lower abdomen since 3-4 days and an ultrasound report s/o 14 weeks abdominal pregnancy with fetal demise.

O/E patient was conscious, oriented, pulse rate 104/min, B.P. 110/70 mm of $\mathrm{Hg}, 3+$ pallor noted. Systemic examination was normal. On per abdominal examination generalised tenderness and guarding were present and exact uterine height was not appreciated. On per speculum examination healthy cervix with closed os and no bleeding found. On per vaginal examination, forniceal tenderness was present and exact uterine size was not appreciated due to tenderness.

Patient had Hb 5 gm \%, WBC Count of 11,400 and Platelet count 1.8 lac/mm3.

AT LAPAROTOMY: Gross hemoperitoneum with 2 litres of blood noted. Fetus was lying free inside abdominal cavity and placenta was attached to ruptured rudimentary uterine horn was non communicating. This was a ruptured second trimester ectopic pregnancy which led to acute abdomen. The ruptured left horn and left sided fallopian tube were removed. 2 units whole transfusion given.

DISCUSSION: The uterus is developed during embryogenesis by the fusion of the two paramesonephric ducts (also called mullerian ducts). The two mullerian ducts fuse into a single uterine body. Lack of fusion or incomplete fusion or defective resorption of the fusion site of these mullerian ducts can lead to various types of malformations of the female genital tract. The incidence of mullerian duct malformations in the general population is estimated to be $4.3 \%$ [ ${ }^{1}$ ] Rudimentary horn pregnancy occurs in approximately $1 / 76000$ to $1 / 150000$ pregnancies.[2,3 ] In a review article, Nahum reported that congenital uterine anomalies affected approximately 1 in 200 women.[3] In such cases, the walls of the abnormal uteri tend to become abnormally thin as pregnancy advances, and the thickness can be inconsistent over different aspects of the myometrium. ${ }^{[2]}$ Uterus bicornis unicollis (bicornuate uterus), which is a common type seen represents a uterine malformation where the uterus is present as a paired organ resulting from the failure of the embryogenic fusion of the cranial part of the mullerian ducts.

Pregnancy in a non communicating rudimentary horn occurs through the transperitoneal migration of the spermatozoon or the transperitoneal migration of the fertilized ovum [5].The first case of uterine rupture associated with rudimentary horn was reported in 1669 by Mauriceau [6]. The timing of rupture varies from 5 to 35 weeks depending on the horn musculature and its ability to hypertrophy and dilate. 70-90\% ruptures before 20 weeks and can be catastrophic [7]. As the uterine wall become thicker and more vascular, bleeding is more severe in ruptured rudimentary horn pregnancy [8]. Kadan and Romano described rudimentary horn rupture as the most significant threat to pregnancy and a life-threatening situation [ $\left.{ }^{9}\right]$. Maternal mortality rate before 1900 was reported to be $47.6 \%$. Rupture of the horn is still common but no case of maternal death has been published since 1960. [10]

Early diagnosis of the condition is essential and can be challenging. Ultrasound, laparoscopy, and MRI are diagnostic tools [11]. Fedele et al. have found ultrasonography to be useful in the diagnosis [12]. But the sensitivity of ultrasound is only $26 \%$ and sensitivity 
decreases as the pregnancy advances. Uterine malformation is usually associated with urinary tract malformation. Sonography for urinary tract should always be done.

Early pre rupture diagnosis is therefore very important. The following criteria have been suggested by Tsafri et al for sonographic diagnosis of rudimentary horn pregnancy [ 4]: (1) pseudopattern of an asymmetrical bicornuate uterus, (2) absent visual continuity between the cervical canal and the lumen of the pregnant horn, and (3) the presence of myometrial tissue surrounding the gestational sac.

Rupture in such cases occurs because of inability of malformed uterus to stretch as a normal uterus. A mid trimester rupture generally occurs at fundus as against lower segment rupture during labour. Rarely, twin gestation can occur in double uterus in which each horn of the uterus carries a pregnancy separately leading to live delivery. The haemorrhage occurring because of rupture is massive and can be life threatening, unless diagnosed and treated promptly. Treatment usually involved is excision of ruptured horn. Immediate resuscitation and early intervention can save the life of the mother. As it leaves a scar on upper segment of the uterus, it is important to avoid pregnancy for at least one year by barrier or hormonal contraceptives

CONCLUSION: Uterine abnormalities though rare can be encountered in pregnancy. Attempts should be made for early diagnosis to avoid maternal mortality. Ultrasonography may be helpful in diagnosing such anomalies before rupture which will help in decreasing the morbidity and mortality. There is a need to build capacity for making an antenatal diagnosis in order to ensure appropriate management.

A documentation of the anomaly encountered during a caesarean or laparotomy for other indications can keep the obstetrician alert in further pregnancies

\section{REFERENCES:}

1. Grimbizis GF, Camus M, Tarlatzis BC, Bontis JN,,Devroey P. Clinical implications of uterine malformation and hysteroscopic treatment results. Hum Reprod Update 2001; 7:161-174.

2. Ural SH, Artal R. Third-trimester rudimentary horn pregnancy. A case report, J Reprod Med 1998; 37: 919-921.

3. Nahum GG. Rudimentary uterine horn pregnancy. A case report on surviving twins delivered eight days apart. J Reprod Med 1997; 42: 525-532

4. Tsafrir A, Rojansky N, Sela HY, Gomori JM, Nadjari M. Rudimentary horn pregnancy: first trimester prerupture sonographic diagnosis and confirmation by magnetic resonance imaging. J Ultrasound Med $2005 ;(2): 219-23$.

5. M. Scholtz, "A full-time pregnancy in a rudimentary horn ofthe uterus," British Journal of Obstetrics \& Gynaecology, vol. 58,pp. 293-296, 1951.

6. F. Mauriceau, Traite des maladaies des femmes grosses, vol. 1, Compaigne des libraries, Paris, France, 1721

7. S. Chowdhury, T. Chowdhury, and E. Azim, "Pregnancy ina non-communicating rudimentary horn of uterus: a clinical case report," Bangladesh Medical Journal, vol. 39, no. 1, pp. 47-48, 2010. 
8. Y. Kadan and S. Romano, "Rudimentary horn pregnancy diagnosed by ultrasound and treated by laparoscopy - a case report and review of the literature," Journal of Minimally Invasive Gynecology, vol. 15, no. 5, pp. 527-530, 2008.

9. G. Nahum, "Rudimentary uterine horn pregnancy: the 20thcentury worldwide experience of 588 cases," Journal of Reproductive Medicine, vol. 47, no. 2, pp. 151-163, 2002.

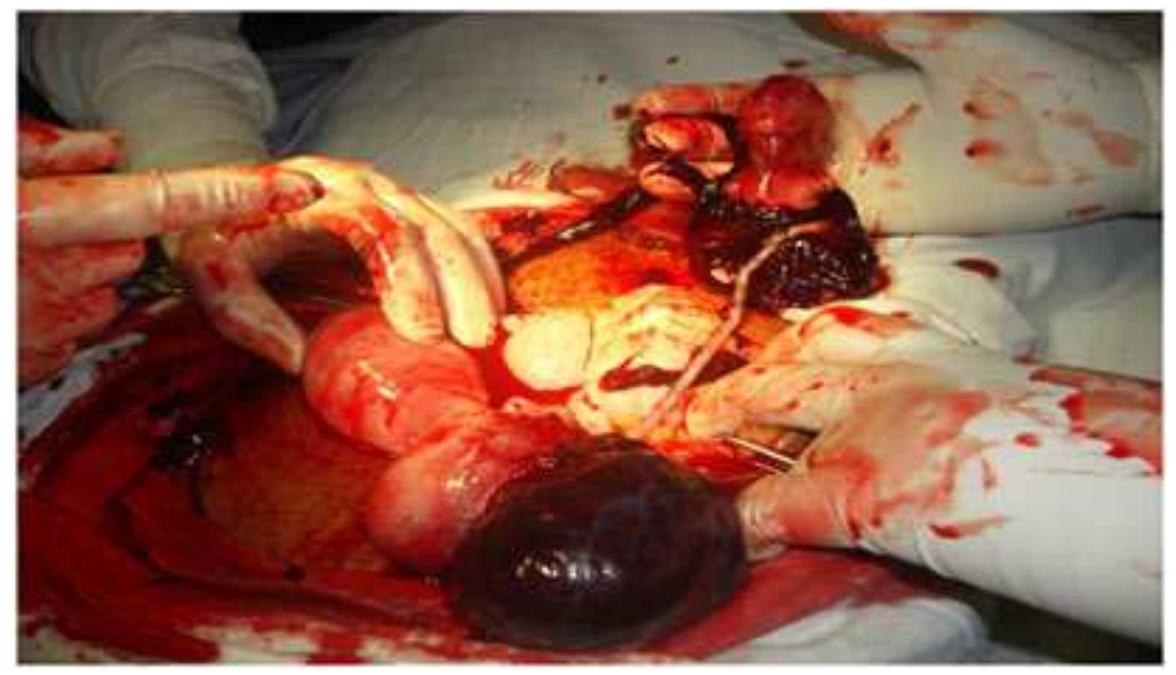

Fetus with rupture horn after LAPAROTOMY section
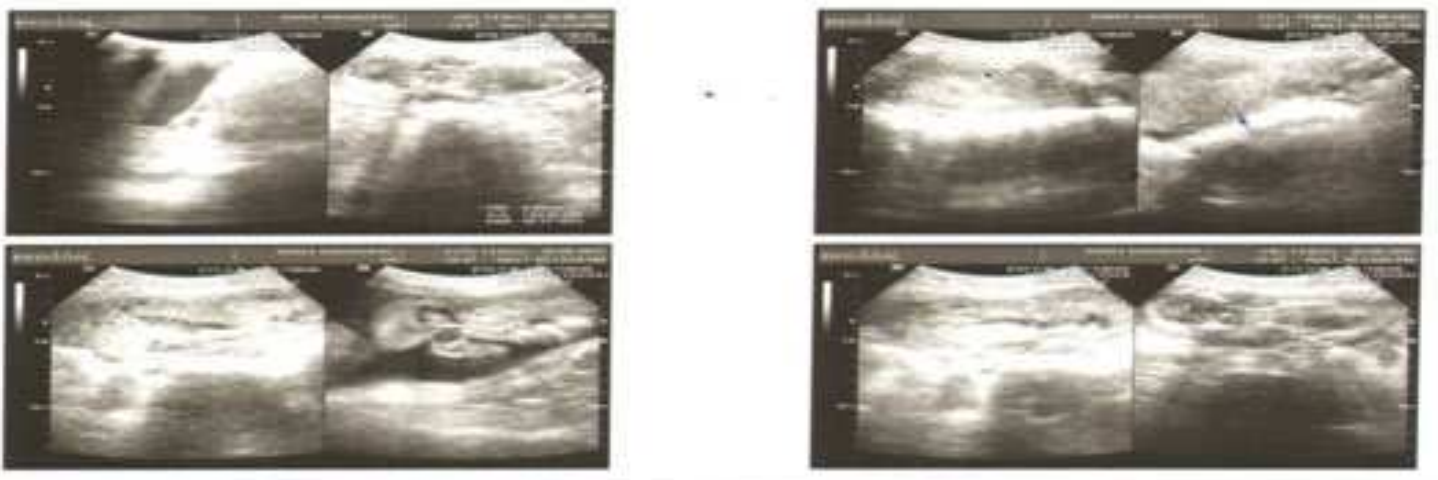

USG showing fetus outside the uterine cavity before LAPAROTOMY section 